\title{
Creep-Testing Foils and Sheets of Alloy 625 for Microturbine Recuperators
}

\author{
Neal D. Evans, Philip J. Maziasz, John P. Shingledecker \\ Oak Ridge National Laboratory; Oak Ridge, TN 37831-6376
}

\begin{abstract}
Microturbines are an attractive alternative for both distributed power generation and combined heat and power applications. Recuperators are compact, high efficiency heat-exchangers which improve the efficiency of microturbines and smaller gas turbines. However, recuperators are also costly and challenging components of such systems which limit maximum operating temperature and lifetime. Because thinner foils make such heat exchangers more compact and efficient, foils on the order of $0.076-0.254 \mathrm{~mm}(0.003-0.010 \mathrm{in}$. $)$ are needed and used for this application. The processing necessary to produce fine-grained foils makes them quite different compared to traditional, heavier section wrought products, with the initial as-processed foil microstructures (e.g. grain size, precipitate morphology, precipitate distribution, etc.) determining the creep properties of such foils during service. For this study, creep-rupture tests in air at 750\\176;C and $100 \mathrm{MPa}$ are being performed on: lab-scale processed $0.102 \mathrm{~mm}(0.004$ in.) thick foil, $0.102 \mathrm{~mm}$ commercial fine-grain foil and $0.254 \mathrm{~mm}$ commercial sheet of alloy 625. These creep-test results, where form-dependent behavior is observed, will be correlated to microstructures of both as-processed and creep-tested specimens, as characterized by analytical electron microscopy. Research supported (NDE, PJM, JPS) by the Office of Distributed Energy and Electricity Reliability under the Assistant Secretary for Energy Efficiency and Renewable Energy, and the Division of Materials Sciences and Engineering (ORNL SHaRE User Facility), U.S. Department of Energy, under contract DE-AC05-00OR22725 with UT-Battelle, LLC.
\end{abstract}

